\title{
Prevalence and Faecal Egg Counts of Gastrointestinal Parasites of Merino Sheep in Lesotho
}

\author{
Mots'elisi Aloycia Mahlehla ${ }^{1 *}$, Setsumi Mots'oene Molapo ${ }^{1}$, Wycliffe Mpho Phoofolo ${ }^{2}$, Puleng Agathah \\ Matebesi $^{1}$, Moeketsi Phalatsi ${ }^{2}$, and Morai Johann Moiloa ${ }^{1}$ \\ ${ }^{1}$ Department of Animal Sciences, National University of Lesotho, P.O.Roma 180, Lesotho \\ ${ }^{2}$ Department of Biology, National University of Lesotho, P.O. Roma 180, Lesotho \\ *Corresponding author's Email: motselisimahlehla@gmail.com; DORCiD: 0000-0001-6898-8236
}

\begin{abstract}
The present study aimed to evaluate the effect of the agroecological zone, host age, and gender on the prevalence and faecal egg load of gastrointestinal parasites (GIPs) for six months (July to December) in the Maseru and Quthing districts, Lesotho. A total of 1919 faecal samples were examined using the McMaster technique. The data were analyzed through generalized estimating equations (GEE) under the binary logistic regression model to determine the significant differences for the GIPs prevalence. Moreover, faecal egg counts (FEC) data were analyzed for repeated measures using GEE. In total, three types of GIPs, namely nematodes, coccidia, and cestodes were identified in this study. The overall prevalence rates of nematodes, coccidia, and cestodes were $53.9 \%, 46.5 \%$, and $4.3 \%$ in the Maseru district, respectively. Furthermore, the Quthing district indicated the prevalence rates of $65.0 \%$, $38.2 \%$, and $0.9 \%$ for nematodes, coccidia, and cestodes, respectively. In the Maseru district, the overall faecal egg counts for nematodes, coccidia, and cestodes were within the ranges of 0-20.3, 0-90, and 0-600 eggs per gram, respectively. Additionally, the faecal egg counts in the Quthing district ranged from 0 to $8.000,6.700$, and 2.000 eggs per gram for nematodes, coccidia, and cestodes, respectively. The majority of the Merino sheep ( $>69 \%)$ in both districts had lower faecal egg counts (100-800) per gram. The agroecological zone affected the nematode infestation in both districts. Coccidia in the Quthing was higher in the mountain areas. In the Maseru district, the nematode infestation was not age-dependent; however, in the Quthing district, the prevalence was higher in juveniles, compared to adults. Age and gender did not affect the prevalence and faecal egg counts of nematodes and coccidia. The coccidian faecal egg loads were higher in females, compared to males. Merino sheep in Lesotho are mostly infected with gastrointestinal nematodes and protozoal coccidia, which could have a tremendous impact on their health and productivity. It is, therefore, of significant importance to develop the deworming strategy for sheep of different age and gender groups in different agroecological zones.
\end{abstract}

Keywords: Age, Agroecological zones, Gastrointestinal parasites, Gender, Lesotho, Prevalence

\section{INTRODUCTION}

Globally, the sheep industry plays a vital role in the economy of countries, especially among the rural poor. However, in both small and large scale farms, gastrointestinal parasites (GIPs) are recognized as significant threats resulting in huge losses to the farming industry (Eke, 2020). In Lesotho, GIPs are said to have caused 16.732 merino sheep deaths during 2013-2014 (Statistical report, 2014). Furthermore, over 32\% of the recorded fatalities occurred in Maseru, which makes it one of the hardest-hit districts, while the Quthing district lost 15\% due to GIPs. Dagnachew et al. (2011) and Hussein et al. (2010) observed the variation of GIPs across the agroecological zones and reported that the lowlands were heavily polluted with GIPs, compared to the foothills and the mountains. On the other hand, Atanásio-Nhacumbe and Sitoe (2019) observed a high prevalence of GIPs in lowlands and mountains with lower faecal egg counts (FEC) in the lowlands, compared to the mountains. The reason for the variation was the competent reproduction and development of gastrointestinal helminths in warm and moist climates. It is reported that the prevalence and FEC of GIPs depend mainly on agroclimatic conditions, host age, host gender, quality and quantity of pasture, and grazing behavior of the host (Tamiru et al., 2018; Mpofu et al., 2020). Haemonchus contortus (nematode species) and Fasciola hepatica (Liver fluke) caused the greatest problem in both lambs and older sheep, especially during humid seasons and climates (Abbott et al., 2012). Lambs were very susceptible to coccidial infections, and it was believed that young sheep were infected by the older ones under poor sanitation and husbandry (Engidaw et al., 2015).

Although GIPs negatively impact the merino sheep production in Lesotho, it has been discovered that there are insufficient or no studies aimed at evaluating the effects of the agroecological zone, age, and gender, on the prevalence and faecal egg load of GIPs of merino sheep. Therefore, this study aimed to investigate the effect of these factors on the prevalence and faecal egg load of GIPs. 
The present study was conducted in the lowlands, foothills, and mountains of agroecological zones of Lesotho, covering the central and southern regions. The lowlands, foothills, and mountains were located in Matsieng, Nyakosoba, and Semonkong in the Maseru district, respectively, while in the Quthing district they were situated in the Quthing town, Mount Moorosi, and Lebelonyane, respectively. The 60 investigated animals were sourced from three farmers per agroecological zone. Following that, they were divided into groups of 20 animals per farmer and further divided equally regarding age (juvenile versus adult) and gender (male versus female).

The selected sheep $(n=360)$ kept under a semi-intensive production system were ear-tagged for easy identification during the monthly collection of the faecal sampling for six months (July to December, 2016). The animals were allowed to graze on communal pastures during the day as a source of nutrition. In the evening they were brought home and housed in kraals. A freshly collected faecal sample was crushed, and out of the whole matter, 2 grams were weighed to be mixed with $58 \mathrm{ml}$ of sodium chloride (Floatation solution). After sieving, a few drops of Amyl Alcohol were added to treat bubbles. Eventually, a sample was drawn with the pipette, put inside the McMaster slide, and then observed under the light microscope. The prevalence of GIPs was calculated by dividing the number of animals harboring a particular parasite by the total number of the investigated sheep. The data were analyzed in SPSS software (version 20.00) using generalized estimating equations (GEE) under the binary logistic regression model to determine the significant differences for the GIPs prevalence. Moreover, the FEC data were analyzed using GEE for repeated measures. Based on the regression models under GEE, a p-value equals to or less than 0.05 was considered statistically significant. It should be noted that the Cestode counts were extremely low to be subjected to a statistical package, consequently, the levels of significance were not reflected against them.

\section{Ethical approval}

The Research and Ethics Committee in the Department of Animal Science at the National University of Lesotho approved this study, based on international animal welfare standards for the use of animals in conducting research.

\section{RESULTS}

\section{Overall prevalence of gastrointestinal parasites}

In total, three types of GIPs, namely nematodes, coccidia, and cestodes, were observed with different infestations over six months. In the Maseru district, the GIP eggs of nematodes, coccidia, and cestodes, ranged between 0 and 20.300, 0 and 90.000, and 0 and 600, respectively. Furthermore, in the Quthing district, the gastrointestinal FEC of nematodes, coccidia, and cestodes ranged from 0 to 8000,0 to 6700 , and 0 to 2000 , respectively.

\section{Prevalence and faecal egg count of gastrointestinal parasites in different agroecological zones}

Table 1 tabulates the recorded prevalence rates of nematodes in the Maseru district that were estimated at $62.35 \%$, $42.94 \%$, and $55.88 \%$, while the abundance values of FECs per gram were determined at 541.6, 212.7, and 459.0 eggs in the lowlands, foothills, and mountains, respectively. The prevalence and FEC in the foothills were significantly lower than those in the lowlands and mountains $(\mathrm{p}<0.05)$.

In the Quthing district, the nematode prevalence rates of $51.52 \%, 78.35 \%$, and $66.67 \%$ were recorded in the lowlands, foothills, and mountains, respectively. Additionally, the mean FEC values of nematodes were estimated at 250.73, 661.01, and 527.47 eggs per gram in the lowlands, foothills, and mountains, respectively. These results showed that the agroecological zone had a significant influence on nematode infection concerning both prevalence and FEC.

The prevalence rates of coccidian infestation were found to be $45.00 \%, 41.72 \%, 52.65 \%$ in the lowlands, foothills, and mountains of the Maseru district, respectively (Table 1). The prevalence of coccidia decreased significantly from the lowlands to the foothills. There was no significant difference between the lowlands and mountains in terms of coccidia prevalence. However, the FEC showed no significant difference in any of the agroecological zones. In the Quthing district, the prevalence rates of coccidia in the lowlands, foothills, and mountains were determined at $34.24 \%, 36.08 \%$, and $45.02 \%$, respectively, while the mean FEC values in these regions were 40.11, 54.08, and 67.28 eggs per gram, respectively. These results revealed a non-significant increase in coccidia prevalence from the lowlands to foothills and mountains ( $p>0.05$ ). However, the results of FEC showed that mountains were significantly more infected, compared to the lowlands and foothills. The prevalence rates of cestodes were $7.65 \%, 4.91 \%$, and $0.29 \%$ in the lowlands, foothills, and mountains of the Maseru district, respectively. In the Quthing district, the cestodes prevalence rates in the lowlands, foothills, and mountains were determined at $1.52 \%, 0.69 \%$, and $0.34 \%$, respectively. 


\section{Prevalence and faecal egg count of gastrointestinal parasites in different sheep age groups}

According to the results of this study (Table 2), in the Maseru district, the prevalence rates of nematodes in adults and juveniles were $55.25 \%$ and $52.50 \%$, respectively. Moreover, the FEC intensity rates were obtained at 432.29 and 325.84 eggs per gram in adults and juveniles, respectively. These results in the Maseru district indicated that age did not influence the prevalence and FEC of nematodes. Sheep reared in the Quthing district had a nematode prevalence of $67.90 \%$ and $61.95 \%$ in adults and juveniles, respectively. However, adults obtained a significantly higher prevalence rate, compared to the juveniles ( $\mathrm{p}<0.05$ ). Additionally, the FECs were obtained at 506.98 and 388.58 eggs in adults and juveniles, respectively; however, there was no significant difference between the two age groups in this regard ( $\mathrm{p}<$ $0.05)$.

In the Maseru district, considering the coccidial infection, the prevalence rates of $40.40 \%$ and $52.69 \%$ were observed in adult and juvenile sheep, respectively (Table 2). In addition, the mean values of FEC were estimated at 79.00 and 313.03 in adult and juvenile sheep, respectively. Generally, the juvenile sheep obtained a significantly higher coccidial infection in both prevalence and FEC, compared to the adult sheep in the Maseru and Quthing districts ( $<$ $0.05)$. In the Quthing district, the prevalence rates of coccidian and mean values of FEC were $32.54 \%$ and $44.03 \%$, as well as 23.50 and 117.94 in adults and juveniles, respectively.

As can be observed in Table 2, in the Maseru district, juvenile sheep were more vulnerable (6.39\%) to the prevalence of cestodes, compared to adult sheep (2.18\%). On the other hand, in the Quthing district, the cestodes prevalence rates were estimated at $0.87 \%$ and $0.88 \%$ in adult and juvenile sheep, respectively.

\section{Prevalence and faecal egg count of gastrointestinal parasites in different gender groups of sheep}

In the Maseru district, the prevalence rates of nematode eggs were $56.14 \%$ and $51.93 \%$ in male and female sheep, respectively (Table 3). Moreover, the mean FEC values were determined at 355.95 and 395.71 in male and female sheep, respectively. Accordingly, prevalence and FEC were not significantly influenced by sexual orientation ( $\mathrm{p}>0.05)$. A similar trend of the results was also observed in the Quthing district with prevalence rates of $66.53 \%$ and $63.54 \%$ in males and females, respectively. Additionally, the FEC values were estimated at 437.38 and 450.36 in male and female sheep, respectively.

In the Maseru district, the coccidial infection showed prevalence rates and FEC values of $45.03 \%$ and $48.07 \%$ as well as 140.80 and 175.63 eggs in males and females, respectively. The Quthing district observed the coccidial prevalence rates of $39.03 \%$ and $37.50 \%$ in males and females, respectively. Moreover, the male and female sheep obtained mean FEC values of 50.62 and 54.75 eggs per gram, respectively. Although the differences between both districts were not statistically significant in terms of the prevalence rates $(p>0.05)$, the results indicated that gender had a significant effect on the mean FEC values in both districts $(\mathrm{p}<0.05)$. The prevalence rates of cestodes in the Maseru and Quthing districts were also estimated at $5.68 \%$ and $2.92 \%$ as well as $1.46 \%$ and $0.23 \%$ in females and males, respectively (Table 3).

Table 1. Agroecological zones effect on prevalence and faecal egg counts of Merino sheep's GIPs in the Maseru and Quthing districts, Lesotho

\begin{tabular}{|c|c|c|c|c|c|c|}
\hline \multirow{2}{*}{$\begin{array}{l}\text { Agro-ecological } \\
\text { zone }\end{array}$} & \multicolumn{3}{|c|}{ Maseru district } & \multicolumn{3}{|c|}{ Quthing district } \\
\hline & $\begin{array}{c}\text { Samples } \\
\text { examined }\end{array}$ & Prevalence \% & EMM of FEC & $\begin{array}{c}\text { Samples } \\
\text { examined }\end{array}$ & Prevalence \% & EMM of FEC \\
\hline \multicolumn{7}{|l|}{ Nematodes } \\
\hline Mountains & 340 & $55.88^{\mathrm{a}}$ & $459.00^{\mathrm{a}}$ & 291 & $66.67^{\mathrm{a}}$ & $527.47^{\mathrm{a}}$ \\
\hline Foothills & 326 & $42.94^{\mathrm{b}}$ & $212.65^{\mathrm{b}}$ & 291 & $78.35^{\mathrm{b}}$ & $661.01^{\mathrm{b}}$ \\
\hline Lowlands & 340 & $62.35^{\mathrm{a}}$ & $541.59^{\mathrm{a}}$ & 331 & $51.52^{\mathrm{c}}$ & $250.73^{c}$ \\
\hline \multicolumn{7}{|l|}{ Coccidia } \\
\hline Mountains & 340 & $52.65^{\mathrm{b}}$ & $106.01^{\mathrm{a}}$ & 291 & $45.02^{\mathrm{a}}$ & $67.28^{\mathrm{a}}$ \\
\hline Foothills & 326 & $41.72^{\mathrm{a}}$ & $179.05^{\mathrm{a}}$ & 291 & $36.08^{\mathrm{a}}$ & $54.08^{\mathrm{b}}$ \\
\hline Lowlands & 340 & $45.00^{\mathrm{b}}$ & $204.85^{\mathrm{a}}$ & 331 & $34.24^{\mathrm{a}}$ & $40.11^{\mathrm{b}}$ \\
\hline \multicolumn{7}{|l|}{ Cestodes } \\
\hline Mountains & 340 & 0.29 & - & 291 & 0.34 & - \\
\hline Foothills & 326 & 4.91 & - & 291 & 0.69 & - \\
\hline Lowlands & 340 & 7.65 & - & 331 & 1.52 & - \\
\hline
\end{tabular}

Values within rows followed by a different superscript ( $a, b, c)$ differed significantly $(\mathrm{p}<0.05)$ from each other. EMM=Estimated Marginal Means, FEC: Faecal Egg Counts, GIPs: Gastrointestinal Parasites. 
Table 2. Effect of Merino sheep age on the prevalence and fecal egg counts of GIPs in the Maseru and Quthing districts, Lesotho

\begin{tabular}{|c|c|c|c|c|c|c|}
\hline \multirow[b]{2}{*}{ Age } & \multicolumn{3}{|c|}{ Maseru district } & \multicolumn{3}{|c|}{ Quthing district } \\
\hline & $\begin{array}{c}\text { Samples } \\
\text { examined }\end{array}$ & Prevalence \% & EMM of FEC & $\begin{array}{c}\text { Samples } \\
\text { examined }\end{array}$ & Prevalence \% & EMM of FEC \\
\hline \multicolumn{7}{|c|}{ Nematodes } \\
\hline Adults & 505 & $55.25^{\mathrm{a}}$ & $432.2^{\mathrm{a}}$ & 461 & $67.90^{\mathrm{a}}$ & $506.98^{\mathrm{a}}$ \\
\hline Juvenile & 501 & $52.50^{\mathrm{a}}$ & $325.8^{\mathrm{a}}$ & 452 & $61.96^{\mathrm{b}}$ & $388.58^{\mathrm{a}}$ \\
\hline \multicolumn{7}{|l|}{ Coccidia } \\
\hline Adults & 505 & $40.40^{\mathrm{a}}$ & $79.00^{\mathrm{a}}$ & 461 & $32.54^{\mathrm{a}}$ & $23.50^{\mathrm{a}}$ \\
\hline Juvenile & 501 & $52.69^{\mathrm{b}}$ & $313.0^{\mathrm{b}}$ & 452 & $44.03^{\mathrm{b}}$ & $117.94^{b}$ \\
\hline \multicolumn{7}{|l|}{ Cestodes } \\
\hline Adults & 505 & 2.18 & & 461 & 0.87 & \\
\hline Juvenile & 501 & 6.39 & & 452 & 0.88 & \\
\hline
\end{tabular}

Table 3. Effect of Merino sheep gender on the prevalence and fecal egg counts of GIPs in the Maseru and Quthing districts, Lesotho

\begin{tabular}{|c|c|c|c|c|c|c|}
\hline \multirow[b]{2}{*}{ Sex } & \multicolumn{3}{|c|}{ Maseru district } & \multicolumn{3}{|c|}{ Quthing district } \\
\hline & $\begin{array}{c}\text { Samples } \\
\text { examined }\end{array}$ & Prevalence \% & $\begin{array}{c}\text { EMM of } \\
\text { FEC }\end{array}$ & $\begin{array}{l}\text { Samples } \\
\text { examined }\end{array}$ & Prevalence \% & $\begin{array}{c}\text { EMM of } \\
\text { FEC }\end{array}$ \\
\hline \multicolumn{7}{|l|}{ Nematodes } \\
\hline Male & 513 & $56.14^{\mathrm{a}}$ & $355.95^{\mathrm{a}}$ & 433 & $66.53^{\mathrm{a}}$ & $437.38^{\mathrm{a}}$ \\
\hline Female & 493 & $51.93^{\mathrm{a}}$ & $395.71^{\mathrm{a}}$ & 480 & $63.54^{\mathrm{a}}$ & $450.36^{\mathrm{a}}$ \\
\hline \multicolumn{7}{|l|}{ Coccidia } \\
\hline Male & 513 & $45.03^{\mathrm{a}}$ & $140.80^{\mathrm{a}}$ & 433 & $39.03^{\mathrm{a}}$ & $50.62^{\mathrm{a}}$ \\
\hline Female & 493 & $48.07^{\mathrm{a}}$ & $175.63^{\mathrm{b}}$ & 480 & $37.50^{\mathrm{a}}$ & $54.75^{\mathrm{b}}$ \\
\hline \multicolumn{7}{|l|}{ Cestodes } \\
\hline Male & 513 & 2.92 & & 433 & 0.23 & \\
\hline Female & 493 & 5.68 & & 480 & 1.46 & \\
\hline
\end{tabular}

\section{DISCUSSION}

According to a study conducted by Regassa et al. (2006), GIPs prefer humid and warm climates due to their larval development and multiplication in the presence of a susceptible host. This could explain the reason for the higher prevalence and FEC of GIPs in the lowlands in the present study. In the mountains, the prevalence was lower due to the cold, which did not favor the survival of gastrointestinal nematode larvae. This pattern was normally based on the nematodes' survival conditions and their life stages. These results comply with the consensus that GIPs vary widely from region to region, corresponding to agroecological zones and climatic diversity, as well as host availability. Furthermore, the mountain areas of Lesotho were prone to snowfall, which kept this area cold (Lesotho Meteorological Services, 2013). The GIPs in the Quthing district were affected by the agroecological zone since the nematode prevalence and FEC were higher in foothills, followed by mountains and lowlands. These results were consistent with the findings of a study performed by Regassa et al. (2006) who also found a high prevalence and FEC of GIPs in the mid-altitudes in their study. The reason for the lower prevalence in the lowlands might be due to the effect of the Senqu Valley region in the Quthing district, which lies predominantly in the lowlands than any other agroecological zones. More coverage in a region leads to the colder condition that does not favor larval development. Despite the higher altitude of the foothills, compared to the lowlands, the nematode prevalence and FEC were higher in the foothills. This might be due to the fact that the foothills were warmer, compared to the lowlands in the Quthing district, since the lowlands had an average winter temperature of $-6.30{ }^{\circ} \mathrm{C}$, while it was $-0.60{ }^{\circ} \mathrm{C}$ in the foothills (Lesotho Meteorological Services, 2013).

Faecal coccidial egg counts were higher in the lowlands of Maseru, followed by foothills and mountains; however, the differences were not significant $(\mathrm{p}>0.05$ ). According to the results presented in Table 1, the prevalence of coccidia was high in the mountains, compared to other agroecological zones. This high rate of coccidia prevalence in the mountains shows that a higher percentage of sheep were infected with coccidia in the mountains; however, the intensity or severity of infection was low, compared to the sheep in the lowlands. This scenario could be traced back to the style and practice of dosing against coccidial infections by farmers in different areas. 
Similar results were also observed in the studies carried out by Whittier et al. (2009), and Dagnachew et al. (2011) who reported that coccidial infection was risky and rapidly multiplying when host animals were under stress due to cold or any disease that could impair the immune response. This result was in line with the findings of a study conducted by Yakhchali and Zarei (2008) who indicated that coccidial oocysts preferred the rainfall but with lower temperature and relatively high humidity. Another trend for coccidial infection was noted in the Quthing district in which the FEC and prevalence rates were higher in the mountains, compared to the lowlands $(\mathrm{p}<0.05)$.

In the same line, Koinari et al. (2013) indicated the higher number of coccidian oocysts (Eimeria) in the mountains, compared to other agroecological zones. These results demonstrated that a higher prevalence of coccidia led to a higher degree of infestation. In other words, there was a positive correlation between prevalence and infestation. The prevalence of cestodes in the Maseru and Quthing districts decreased from the lowlands to the mountains and behaved more or less like the nematodes. This finding was consistent with the results of a study performed by Owen (1989) who revealed that Platyhelminthes species were more prevalent in the lowlands, compared to mountains, owing to the warm and humid areas.

Villarroel (2013), and Tehmina et al. (2014) conducted studies on the host age factor and indicated that two-yearold sheep had a higher prevalence and FEC of gastrointestinal helminths, compared to juveniles. The higher prevalence of nematodes in adults, although not significant, might have arisen from the fact that older sheep get the infectious larval stage of helminths on the rangelands, where they grazed with other animal species. In most cases, juveniles were often left behind at home to be fed.

Coccidian infection was significantly higher in juvenile, compared to adult sheep in both districts ( $<<0.05)$. This implied that juveniles were highly susceptible to coccidia because of their weaker immunological response to severe infections. The results accorded with the report of Kyriánová et al. (2017) who found a higher overall prevalence of coccidia species in lambs and female sheep. Adult sheep were exposed to repeated infections, and therefore, might have developed immunity to coccidial infections. These results were also consistent with the findings of the studies carried out by Vlassoff et al. (2001), and Etsay et al. (2020) who reported a higher prevalence and FEC of coccidia in lambs, compared to adult sheep. In the same vein, Yakhchali and Zarei (2008) indicated that coccidia species were frequently found in faecal samples; however, their occurrence is influenced by the age and immunity status of a host, which was mainly observed in juveniles in the present study. Farmers' management, including sanitation, low availability of clean pasture, and stress could also be an influencing factor (Odden et al., 2017). Juveniles might catch the infection from suckling soiled teats of a dam if the kraal was not regularly cleaned and disinfected.

Similarly, cestodeal infections were higher in juveniles, compared to adults, which confirmed the fact that juveniles were highly susceptible to gastrointestinal helminths due to their weaker immunity. In the present study, some lambs grazed with adults in a communal grazing system, which exposed them to mild infection. In the studies conducted by Maingi and Munyua (1994), Craig et al. (2006), and Hashemnia et al. (2014), nematode and coccidial infections of lambs were reported, which was consistent with the results of the current study. They explained that male sheep were prone to gastrointestinal helminths because of the production of androgen hormones, which seem to suppress the immune response of the male sheep.

Lashari and Tasawar, (2011) reported that the production of estrogen by female sheep stimulated their immune response. This might also explain the low prevalence rate of infection in females. In addition, Zeryehun (2012) indicated a higher prevalence of gastrointestinal helminths in rams. However, the higher FEC for coccidia in females could probably be traced to the fact that females became susceptible to parasitic diseases because of lower immunity during pregnancy and parturition (Parkins and Holmes, 1989; Dugassa et al., 2018).

\section{CONCLUSION}

Merino sheep in Lesotho are mostly infected with gastrointestinal nematodes and protozoan coccidia, which could have a tremendous impact on their health and productivity. The gastrointestinal prevalence correlated positively with the faecal egg loads. Nematodes and coccidia infestations were higher in the lowlands and foothills of the Maseru and Quthing districts, respectively. Moreover, adult sheep were more infected with nematodes, while coccidian was prevalent in juveniles. Males and females were equally affected by gastrointestinal parasites. Therefore, it is of significant importance to developing a dosage schedule for sheep of different ages and gender groups in different agroecological zones.

\section{DECLARATIONS}

\section{Acknowledgments}

The authors are grateful to the Regional Universities Forum for Capacity Building in Agriculture (RUFORUM) for funding this research through grant No.RU 2015 GRG-109. Farmers are also acknowledged for making their animals available for this study.

\section{Competing interests}


The authors declared that they have no conflict of interest.

\section{Consent to publish}

All authors approved the final version of the manuscript before submission.

\section{Author's contribution}

Mots'elisi Aloycia Mahlehla and Setsumi Mots'oene Molapo participated in the data collection, analysis, preparation, and revision of the manuscript. Moeketsi Phalatsi and Moiloa Johannes Moiloa involved in the collection of data and laboratory analysis, while Mpho Wycliffe Phoofolo and Puleng Agathah Matebesi conceptualized and designed the experiment.

\section{REFERENCES}

Abbott KA, Taylor M, and Stubbings LA (2012). Sustainable worm control strategies for sheep. 4th Edition. Sustainable Control of Parasites in Sheep, United Kingdom, Pp. 5-10. Available at: http://www.scops.org.uk

Atanásio-Nhacumbe A, and Sitoe CF (2019). Prevalence and seasonal variations of eggs of gastrointestinal nematode parasites of goats from smallholder farms in Mozambique. Insights Veterinary Science, 3: 23-29. DOI: https://www.doi.org/10.29328/journal.ivs.1001016

Craig BH, Pilkington JG, and Pemberton JM (2006). Gastrointestinal nematodes species burdens and host mortality in feral sheep population. Institution of Evolutionary Biology, 133(4): 485-496. DOI: https://www.doi.org/10.1017/S0031182006000618

Dagnachew, S., Amamute, A. and Temesgen, W. 2011. Epidemiology of gastrointestinal helminthiasis of small ruminants in selected sites of North Gondar zone, Northwest Ethiopia. Ethiopia Veterinary Journal 15 (2): 57-68. DOI: 10.4314/evj.v15i2.67694

Dugassa J, Hussein A, Kebede A, and Mohammed C (2018). prevalence and associated risk factors of gastrointestinal nematodes of sheep and goats in ZiwayDugda District, Eastern Arsi Zone of Oromia Regional State, Ethiopia. ournal of Animal and Veterinary Sciences, 4(2): 6-18. DOI: https://www.doi.org/10.20431/2455-2518.0402002

Eke SS, Omalu ICJ, Ochaguba JE, Urama AC, Hassan SC, Otuu CA and Okafor ID (2020). Gastrointestinal Helminths Infections in Small Ruminants Slaughtered in Minna Modern Abattoir, North Central, Nigeria. Journal of Animal and Veterinary Sciences, 7 , (3): 13-18. https://doi.org/10.31248/JASVM2019.131

Engidaw S, Anteneh M, and Demis C (2015). Coccidiosis in Small Ruminants. African Journal of Basic and Applied Sciences, 7(6): 311-319. DOI: https://www.doi.org/10.5829/idosi.ajbas.2015.7.6.96202

Etsay K., Megbey S, and Yohannes H (2020). Prevalence of sheep and goat coccidiosis in different districts of Tigray region, Ethiopia. Nigerian Journal of Animimal Science, 22(3): 61-69. Available at: https://www.ajol.info/index.php/tjas

Hashemnia M, Rezaei F, Chalechale A, Kakaei S, and Gheichivand S (2014). Prevalence and intensity of eimeria infection in sheep in western Iran. International Journal of Livestock Research, 4(1): 107-112. DOI: https://www.doi.org/10.5455/ijlr.20140109084416. [Google Scholar]

Hussein ANA, Hassan IM, and Khalifa RMA (2010). Description of eggs and larval stages of Fasciola, light and scanning electron microscopic studies. Research Journal of Parasitology, 5: 1-12. DOI: https://www.dx.doi.org/10.3923/jp.2010.1.12

Koinari M, Karl S, Ryan U, and Lymbery AJ (2013). Infection levels of gastrointestinal parasites in sheep and goats in Papua New Guinea. Journal of Helminthology, 87(4): 409-415. DOI: https://www.doi.org/10.1017/S0022149X12000594

Kyriánová IA, Vadlejch J, and Langrová I (2017). Eimeriosis seasonal dynamics patterns at an organic sheep farm in the czech republic. Scientia Agriculturae Bohemica, 48(2): 70-75. DOI: https://www.doi.org/10.1515/sab-2017-0013

Lashari MH, and Tasawar Z (2011). Prevalence of some gastrointestinal parasites in sheep in Southern Punjab, Pakistan. Pakistan Veterinary Journal, 31: 295-298. Available at: http://search.ebscohost.com/login.aspx?direct=true\&site=eds$\underline{\text { live } \& \mathrm{db}=\mathrm{asn} \& \mathrm{AN}=66654640}$

Lesotho Meteorological Services (LMS) (2013). The climate of Lesotho: Ministry of energy, meteorology and water affairs, Lesotho. Pp. 1-35. Available at: http://extwprlegs1.fao.org/docs/pdf/les184526.pdf

Maingi N, and Munyua WK (1994). The prevalence and intensity of infection with Eimeria species in sheep in the Nyandarua district of Kenya. Veterinary Research Communications, 18: 19-25. DOI: https://www.doi.org/10.1007/BF01839257

Mpofu TJ, Nephawe KA, and Mtileni B (2020). Prevalence of gastrointestinal parasites in communal goats from different agroecological zones of South Africa. Veterinary World, 13(1): 26-32. DOI: https://www.doi.org/10.14202/vetworld.2020.26-32.

Odden A, Enemark HL, Robertson LJ, Ruiz A, Hektoen L, and Stuen S (2017). Treatment against coccidiosis in Norwegian lambs and potential risk factors for development of anticoccidial resistance. A questionnaire-based study. Parasitology Research, 116(4): 1237-1245. DOI: https://www.doi.org/10.1007/s00436-017-5400-7

Owen IL (1989). The epidemiology of fasciolosis in Papua New Guinea. Australian Veterinary Journal, 66: 58-60. Available at: http://agris.fao.org/agris-search/search.do?recordID=AU8903256

Parkins J, and Holmes P (1989). Effects of gastrointestinal helminths parasites on ruminant's nutrition. Nutrition Research Reviews, 2 : 227-246. DOI: https://www.doi.org/10.1079/NRR19890016

Regassa F, Sori T, Dhuguma R, and Kiros Y (2006). Epidemiology of gastrointestinal parasites of ruminants in western Oromia, Ethiopia. International Journal Applied Research Veterinary Medicine, 4(1): 51-57. Available at: http://www.jarvm.com/articles/Vol4Iss1/Vol4Iss1RegassaV4N1pp51-57.pdf 
Statistical report (2014). Lesotho Livestock Statistics Report. Bureau of Statistics, 8: 6-10. Available at: http://www.bos.gov.ls/new\%20folder/Copy\%20of\%20Agriculture/2013_14_livestock_report.pdf

Tamiru Y, Tibebu A, and Abdeta A (2018). Prevalence of Major Gastrointestinal Nematode and Degree of Parasite Infestation in Sheep of Bako Agricultural Research Center Community Based Breeding Program Project Small Holder Farms at Horro District. Dairy and Veterinary Science Journal, 8(3): 1-12. DOI: http://dx.doi.org/10.19080/JDVS.2018.08.555740

Tehmina S, Shahina R, Razzaq A, Marghazani IB, and Khosa AN (2014). Prevalence of Paramphistomum cervi in different sheep breeds of Balochistan (Pakistan). Paramphistomum cervi en ovejas. Revista Veterinaria, 25(1): 12-15. DOI: https://www.doi.org/10.30972/vet.251542

Villarroel A (2013). Internal Parasites in Sheep and Goats. Oregon State University, pp. 1-4. Available at: http://oregonstate.edu https://agsci.oregonstate.edu/sites/agscid7/files/em9055.pdf

Vlassoff A, Leathwick DM, and Heath ACG (2001). The epidemiology of nematode infections of sheep. New Zealand Veterinary Journal, 49: 213-221. DOI: https://www.doi.org/10.1080/00480169.2001.36235

Whittier DW, Zajac A, and Umberger SH (2009). Control of internal parasites in sheep. Virginia Cooperative Extension, pp. 1-8. Available at: http://pubs.ext.vt.edu

Yakhchali M, and Zarei MR (2008). Prevalence of Eimeria infection in sheep of Tabriz suburb. Iran. Iranian Journal of Veterinary Research, 9(3): 277-280. Available at: http://www.shirazu.ac.ir/en/index.php?page_id=60

Zeryehun T (2012). Helminthiasis of sheep and goats in and around Haramaya, Southeastern Ethiopia. Journal of Veterinary Medicine and Animal Health, 4(3): 48-55. DOI: https://doi.org/10.5897/JVMAH12.0014 